Boise State University

ScholarWorks

Educational Technology Faculty Publications and

Presentations

Department of Educational Technology

7-1-2016

Effects of Personalization and Invitation Email Length on Web-Based Survey Response Rates

Jesús H. Trespalacios

Boise State University

Ross A. Perkins

Boise State University 
This is an author-produced, peer-reviewed version of this article. The final, definitive version of this document can be found online at Tech

Trends, published by Springer. Copyright restrictions may apply. doi: 10.1007/s11528-016-0058-z

\title{
Effects of Personalization and Invitation email length on Web-Based Survey Response Rates
}

\author{
Jesús H. Trespalacios \\ Boise State University \\ Ross A. Perkins \\ Boise State University
}

\begin{abstract}
Individual strategies to increase response rate and survey completion have been extensively researched. Recently, efforts have been made to investigate a combination of interventions to yield better response rates for web-based surveys. This study examined the effects of four different survey invitation conditions on response rate. From a large metropolitan university in the West, a group of 1,598 selected students were randomly assigned to four groups, each of which received a different version of the invitation email to participate in a survey of campus technology needs. Findings show that neither the degree of personalization nor the length of the invitation email impacted survey response or completion. Additionally, the outcomes demonstrated the impact of research-based "best practices" and their impact on overall response rate.
\end{abstract}

\section{Introduction}

In the field of educational or instructional technology, a number of studies are done each year that make use of webbased (or "online") surveys. A search of dissertations in the field using online surveys went from a total of 68 for all years up to 2010, to nearly 140 since that time. A search of articles shows 33 published in all years before 2010, and nearly half that just in the last five years. Given the growing trend in educational technology to use electronic surveys to collect data, it behooves researchers to examine all means to increase the validity and reliability of such tools, as well as examine how the administration of such surveys might be ameliorated. A critical goal of survey administration is to increase the credibility of results (Burkell, 2003; Baruch \& Holtom, 2008), and one obvious way to increase credibility is to take measures to ensure a high response rate and survey completion.

A number of interventions to increase response rate have been investigated. Those that have been shown to make a significant difference in response rates include the use of incentives (Bosnjak \& Tuten, 2003; Church, 1993; Dillman, 2007; Heerwegh, 2006), increasing the number of contacts with participants (Klofstad, Boulianne, \& Basson, 2008; Dillman, 2007); personalization of invitations (Dillman, 2007; Heerwegh \& Loosveldt, 2007; Heerwegh, Vanhove, Matthijs \& Loosveldt, 2005; Joinson, Woodley, \& Reips, 2007), and well-crafted invitation messages, which includes the trustworthiness of the sender (Porter \& Whitcomb, 2005; Trouteaud, 2004; Tuten, 1997). However, none of these interventions, by itself, trumps the others with regard to effectiveness, and conflicting reports of effectiveness exist. Therefore, researchers recommend a multifactorial solution to yield better response rates for web-based surveys (Dillman, 2007; Fan \& Yan, 2010; Marcus, Bosnjak, Lindner; Perkins, 2011; Pilischenko \& Shutz, 2007). In many cases, all of the solutions found in literature are not possible given that researchers do not always have a means of accounting for all of the information needed to enact them.

Within higher education, a number of means to contact potential study participants exist, especially if the population and sample are members of the university or college's community. The availability of user data (i.e., from a backend student information database) and tools to make solicitations highly personal (i.e., online survey software), etc. are available, but does that imply we should use such data and tools? Will time invested in personalization or crafting of explanatory emails result in increased rates of response? The study described in this paper examined the impact of personalization of invitation emails and length of initial message on survey response, and included additional analyses 
This is an author-produced, peer-reviewed version of this article. The final, definitive version of this document can be found online at Tech Trends, published by Springer. Copyright restrictions may apply. doi: 10.1007/s11528-016-0058-z

based on the population demographics and non-completing respondents. Thus, the following research question was investigated: Are there significant differences in the survey response rates across the personalization and the length of the initial message?

\section{Theoretical Framework}

\section{Personalization}

Given the capabilities of various web-based survey mechanisms, especially the ability of the surveyor to use relational databases, a good deal more personalization is possible (Joinson, Woodley, \& Reips, 2007). Fan and Yan (2010) described personalization as one of three most studied issues on invitation designs. For example, Joinson and Reips (2007) conducted three different experiments on personalized email invitations salutation. Two of the three experiments showed that personalization increased the response rate on web-based surveys. Heerwegh (2005) divided 2520 students in two groups. The control received the impersonal salutation ("Dear Student”), and the treatment group received the personal salutation including the first and last names. Results showed that personalization significantly increases the web survey response rate. Other studies observed a higher response rate due to personalization, but they were not statistically significant (Pearson \& Levine, 2003; Porter \& Whitcomb, 2003a). Pearson and Levin (2003) found significant differences between age and preferred salutation.

Including sensitive questions in a survey may provide different effect. Heerwegh et al. (2005) found that personalization in email invitation attracts more socially desired answers to sensitive questions in web surveys. In conclusion, it is possible to hypothesize that more personalized emails will increase the response rate on web-based surveys.

\section{$\underline{\text { Invitation Email }}$}

Another variable that may affect the response rate is the type of content sent in the survey email. While much advice and many studies suggest keeping the survey length itself as short as possible (so as to increase completion rates) (Porter, 2004), little has been written about the impact that the invitation message might have on survey response. One example is the study made by Klofstand et al. (2008) where it compared two different email lengths. Authors reported there was not a significant difference between a short email with little information about the survey and a long email with more information about the survey. Moving to a different sector, email has been recognized as an important tool for marketing because of low investment and high response rate. One study in this area found an inverse relationship between response rate and the length of the email (Retti \& Chittenden, 2003).

Besides the length of the email, it is important to take into account other variables in the survey invitation email. For instance, the sender of the email is a variable that may impact survey rate responses. Joinson, Woodlay, and Reips (2007) found that the highest response rate occurred when the sender came from a person with an authoritative position. In another study, Porter and Whitcomb (2005) researched how web survey viewing and response are affected by the information in the email subject lines. Having two different groups based on the level of involvement with the sponsor of the survey, researchers did not find significant differences among the three factors described in the subject line: reason for the contact, mention of the sponsor, and the plea for help.

One might speculate that shorter rather than longer messages would cause an increase in response rate given people's dislike for scrolling (Ducheneaut \& Bellotti, 2001). However, it is still valid to mention that longer solicitations are better (for response) in that they provide participants with more information and are therefore more trustworthy. Uncertainty about how message length may impact response rate leads to questions that can be answered through research.

\section{Methodology}

The experiment was conducted in spring 2011, as part of a survey study looking at personal technology and usage of and feedback about main campus computing labs. A random sample of students $(n=1,598)$ was each sent $\$ 5.00$ as an incentive to participate; the money was provided by the university's Office of Information Technology. Additionally, students who completed the survey were eligible for a $\$ 250$ prize drawing. The sample was drawn from a sample frame of 10,500 students. The frame was created by limiting a population of over 18,000 total students to only those 
This is an author-produced, peer-reviewed version of this article. The final, definitive version of this document can be found online at Tech Trends, published by Springer. Copyright restrictions may apply. doi: 10.1007/s11528-016-0058-z

students who 1) were 18 years of age and older, 2) were degree seeking students, 3) were taking at least one course on the main campus and 4) had not previously been oversampled for survey participation. The students were randomly assigned into groups of approximately equal size.

All group members were sent an email or pre-notification survey that contained a greeting using their first name on a Monday morning simply informing them of an upcoming survey and informing them of forthcoming details of money being added to their personal student ID card and the prize drawing. That evening, the groups received differentiated emails (See Appendix). Three reminders were sent in total - one three days following the initial solicitation, the second five days following the first reminder, and the final survey was sent during spring vacation, one week after the second reminder (nearly two weeks after the initial reminder). No student who had completed the survey received a followup reminder - only those who had not yet opened the link received them. The survey was closed to input approximately four weeks after it was opened (by that time, responses had significantly tapered).

A data file of the randomly selected students was provided to the researchers by the university's institutional assessment and research office. Selected columns from this file were uploaded to the researcher's Qualtrics account to create a relational database of 1,598 names (two students were eliminated as they had participated in pilot testing the survey). The resulting database was used to track response to the survey, as well as to capture the input of those who chose to participate. In all, 726 students completed the survey. The characteristics of completers and noncompleters, as well as the message groups into which they were randomly placed, all existed in the same file. The survey itself contained 44 questions (nine were open-ended). All pre-existing and user-input fields together resulted in a database of more than 110 data fields.

The invitation email sent to students varied in four areas: Group 1 received an email that was highly personalized (first name, year in school cited, major cited, department cited) and had a good deal of survey related information; Group 2 would received an email that had little information about the survey, but had as much personalized information as Group 1. Group 3 received an email that had little personalization (first name in greeting only), but had a good deal of information about the survey itself. Group 4 received an email that had little personalization and little information. Using the web-based survey tool, Qualtrics, the researcher was able to use "piped text" (similar to mail merge fields) to create the various levels of personalization. All emails included a signature block that referred to the campus committee organizing the survey, a link to the survey itself, and a link to a web page that gave more information about the survey.

\section{Results}

Response to this survey was higher than the typical surveys conducted at the university; 740 students opened the survey for an unprecedented $46.3 \%$ response rate. Of these, 14 did not complete the survey, for a response rate of $45.4 \%$. Nearly $82 \%$ of all responses were submitted before the third reminder was sent; another 136 responses were picked up with the final two reminders.

To test the effects of the personalization and the amount of survey information on survey response rates, a chi-square test of independence was conducted. As seen in Table 1 , the survey response rates did not differ significantly $(\mathrm{p}<.05)$ across the two factors $\left(\chi^{2}(1)=.363, \mathrm{p}=.55\right.$; and $\chi^{2}(1)=2.27, \mathrm{p}=.13$, respectively). In other words, sending a personal or impersonal email with low or high level of survey information did not differ response rates significantly.

Table 1. Personalization, survey information and response rates

\begin{tabular}{cccc}
\hline & High personalization & $\begin{array}{c}\text { Little } \\
\text { personalization }\end{array}$ & Total \\
\hline High survey information & $168(23.1 \%)$ & $180(24.7 \%)$ & 348 \\
Little survey information & $189(26.1 \%)$ & $189(26.1 \%)$ & 378 \\
Total & 357 & 369 & 726 \\
\hline
\end{tabular}


This is an author-produced, peer-reviewed version of this article. The final, definitive version of this document can be found online at Tech Trends, published by Springer. Copyright restrictions may apply. doi: 10.1007/s11528-016-0058-z

\section{Demographic Association with Response}

Statistical modeling was used to determine whether any of the identified demographics from the population (personalization, information level, number of cumulative credits earned, ethnicity, gender, and college of current major) were associated with an increased or decreased probability of response. The "best" predictive logistic regression model was identified by Akaike's Information Criterion. The results show that the odds of response drop 40 percent for males and increase about five percent for every unit completed at the university. The odds of response for students in the College of Engineering were about 43 percent higher than respondents from all other colleges. Whether this latter finding is in general true, or an artifact of this specific survey, cannot be known. In fact, the Colleges of Arts and Science and Social Science and Public Affairs are the largest on campus, and the random selection process bears this out (27\% and 23\% of selected students, with 12 percent from the College of Engineering). Importantly, personalization or information was not associated with probability of response. With respect to the experimental groups, statistical tests confirm that the students receiving the four sets of messages were similar in their gender and ethnicity, the distribution of colleges, and the number of accumulated units.

\section{Item Non-Response}

Of the 740 students who opened the survey, 14 did not complete the survey. Five respondents opened the survey, but did not answer any questions. These have been left as "missing" for each question, rather than removed from the survey. One respondent stopped after answering student demographic questions. Two completed questions on personal technology, but stopped at the question requesting reasons for not bringing a laptop to campus. Of the remaining three non-completing respondents, one stopped at the questions on computer lab use and availability, another at the last question on personnel and software in the computer labs, and another after finishing the block of questions on which open computing labs they visited. All questions had some non-response, in addition to the noncompletes described. However, all questions had approximately a one-percent non-response, low enough that question reliability is not in question.

\section{Conclusions}

Heerwegh et al. (2005) summarized two issues regarding the effectiveness of personalization emails. Firstly, experienced computer users might identify when a personalized email invitation has been automatized, losing its effectiveness. It could be a possibility in this study. Since most college students are computer literate and have been exposed to web-based survey invitations, students might recognize these computer-generated emails, losing its effect. And secondly, personalization might produce an opposite effect when the sender is unknown to the user. Because the email was signed by the campus committee organizing the survey, it might be that users do not have a sense of direct relationship with the email sender/survey sponsor.

Although personalization and survey information included in the invitation email did not have an effect on web-based survey response rates, a high response rate was obtained supporting the role of a combination of different variables implemented in the web-based survey. Porter and Umbach (2006) note that studies of interest would examine "how incentives and other survey administration strategies can ameliorate institutional differences in response rates" (p. 244). This is echoed by Fan and Yan (2010), who state "empirical research is needed to examine various response behaviors" (p. 137). The decisions made with regard to the sample frame, the salience of the message, and other administrative factors, which included up-front monetary incentives for all students and pre-notifications emails, resulted in a three-fold increase in survey response. The dramatic increase in response rate in this study gives credence to Dillman's (2007) position that it is not one factor that causes the increase, but a combination of many. The investigation on email personalization and message response length also confirms previous research that examines other elements of email solicitation (e.g., Trouteaud, 2004; Porter \& Whitcomb, 2003a) and extends research into personalization of solicitation messages (e.g., Joinson, Woodley, \& Reips, 2007). 
This is an author-produced, peer-reviewed version of this article. The final, definitive version of this document can be found online at Tech Trends, published by Springer. Copyright restrictions may apply. doi: 10.1007/s11528-016-0058-z

\section{References}

Archer, T. M. (2008). Response rates to expect from web-based surveys and what to do about it. Journal of Extension, 46(3). Retrieved from http://www.joe.org/joe/2008june/rb3.php

Baruch, Y. \& Brooks, C H. (2008). Survey response rate levels and trends in organizational research. Human Relations, 61, 1139-1160. doi: 10.1177/0018726708094863

Bosnjak, M. \& Tuten, T. L. (2003). Prepaid and promised incentives in web surveys: An experiment. Social Science Computer Review, 21, 208-217. doi: 10.1177/0894439303021002006

Burkell, J. (2003). The dilemma of survey nonresponse. Library and Information Science Research, 25(3), 239-263. doi:10.1016/S0740-8188(03)00029-X

Church, A. H. (1993). Estimating the effect of incentives on mail survey response rates: A meta-analysis. Public Opinion Quarterly, 57(1), 62-79. doi: 10.1086/269355

Cook, C., Heath, F., Thompson, R. L. (2000). A meta-analysis of response rates in web- or internet-based surveys. Educational and Psychological Measurement, 60(6), 821-836. doi: 10.1177/00131640021970934

Dillman, D. A. (2007). Mail and Internet surveys: The tailored design method (2nd Ed.). Hoboken, NJ: Wiley.

Doucheneaut, N. \& and Bellotti, V. (2001). Email as habitat: An exploration of embedded personal information management. Interactions, 8(5), 30-38.

Fan, W. \& Zheng, Y. (2010). Factors affecting response rates of the web survey: A systematic review. Computers in Human Behavior, 26(2), 132-139. doi:10.1016/j.chb.2009.10.015

Heerwegh, D. (2006). An investigation of the effect of lotteries on web survey response rates. Field Methods, 18(2), 205-220. doi: 10.1177/1525822X05285781

Heerwegh, D. (2005). Effects of personal salutations in e-mail invitations to participate in a web survey. Public Opinion Quarterly, 69(4), 588-598. doi: 10.1093/poq/nfi053

Heerwegh, D., Vanhove, T., Matthijs, K., \& Loosveldt, G. (2005). The effect of personalization on response rates and data quality in web surveys. International Journal of Social Research Methodology, 18(2), 85-99. doi: 10.1080/1364557042000203107

Joinson, A. N. \& Reips, U-D. (2007). Personalized salutation, power of sender, and response rates to web-based surveys. Computers in Human Behavior, 23(3), 1372-1383. doi:10.1016/j.chb.2004.12.011

Joinson, A. N., Woodley, A., \& Reips, U-D. (2007). Personalization, authentication and self-disclosure in selfadministered Internet surveys. Computers in Human Behavior, 23(1), 275-285. doi:10.1016/j.chb.2004.10.012

Klofstad, C. A., Boulianne, S., \& Basson, D. (2008). Matching the message to the medium. Social Science Computer Review 26(4), 498-509. doi: 10.1177/0894439308314145

Kypros, K., Gallagher, S. J., \& Cashell-Smith, M. L. (2004). An internet-based survey method for college drinking research. Drug and Alcohol Dependence, 76(1), 45-53. doi:10.1016/j.drugalcdep.2004.04.001

Marcus, B., Bosnjak, M., Lindner, S., Pilischenko, S., \& Shütz, A. (2007). Compensating for low topic interest and long surveys. Social Science Computer Review, 25(3), 372-383. doi: 10.1177/0894439307297606

Pearson, J. \& Levine, R. A. (2003). Salutations and response rates to online surveys. Paper presented at the Association for Survey Computing Fourth International Conference on the Impact of Technology on the Survey Process, University of Warwick, England.

Perkins, R. A. (2011). Using research-based practices to increase response rates of web-based surveys. EDUCAUSE Quarterly, 32(2). Retrieved from http://www.educause.edu/eq

Porter, S. R. (2004). Raising response rates: What works? New directions for institutional research, 121, 5-21. doi: 10.1002/ir.97

Porter, S. R. \& Whitcomb, M. E. (2005). Email subject lines and their effect on web survey viewing and response. Social Science Computer Review, 23(3), 380-387. doi: 10.1177/0894439305275912

Porter, S. R. \& Whitcomb, M. E. (2003a). The impact of contact type on web survey response rates. Public Opinion Quarterly, 67(4), 579-588. doi: 10.1086/378964

Porter, S. R. \& Whitcomb, M. E. (2003b). The impact of lottery incentives on student survey response rates. Research in Higher Education, 44(4), 389-407. doi: 10.1023/A:1024263031800

Rettie, R. \& Chittenden, L. (2003). Email marketing: Success factors. Occasional Paper Series No 50. U.K.: Kingston Business School, Kingston University.

Trouteaud, A. R. (2004). How you ask counts: A test of Internet-related components of response rates to a webbased survey. Social Science Computer Review, 22(3), 385-392. doi: 10.1177/0894439304265650

Tuten, T. L. (1997). Getting a foot in the electronic door: Understanding why people read or delete electronic mail (Rep. No. 97/08). Mannheim, Germany: Zentrum fuer Umfragen, Methoden und Analysen. 
This is an author-produced, peer-reviewed version of this article. The final, definitive version of this document can be found online at Tech

Trends, published by Springer. Copyright restrictions may apply. doi: 10.1007/s11528-016-0058-z

\section{Appendix}

Email \#1: High Information \& High Personalization Group

SUBJECT LINE: Your input requested for Student Computing Needs Survey

\section{Hi, \{FIRST NAME\}!}

We recently added \$5.00 to your Card in advance of your kind completion of the survey linked below. When you complete the survey, which should take only 10 to 15 minutes of your time, you can register for a random drawing of $\$ 250$.

As a $\{$ CLASS LEVEL\} $\{$ MAJOR , you have a unique perspective to offer regarding student computing needs on campus. The $\{$ DEPARTMENT $\}$ will benefit from the feedback offered by concerned $\{$ STATUS $\}$ like yourself.

The

Committee, offers recommendations about the distribution of student computer fees to units such as colleges and departments. The reason we have developed the survey is to get student input about information technology resources on campus.

As you might be aware, some of the student fees you pay annually are designated for the maintenance and upgrading of designated labs on campus. But are those fees being used in the best way possible? Are the computing resources located in the right places? Is student access to the technology resources adequate? Are more funds needed for a stronger wireless network as more and more students use laptops or other wireless devices? These are the types of questions that we ask, and we hope that you can provide some insight.

Again, we appreciate your time in helping us better understand the needs you have with regard to on-campus technology resources. This information, in turn, will assist us in forming recommendations about how to put computing fees to the best possible use.

To take the survey, \{SurveyLink\}

Or copy and paste the URL below into your internet browser: \{SurveyLink\}

Best regards,

Members of the Committee

More info: [URL about survey] 
This is an author-produced, peer-reviewed version of this article. The final, definitive version of this document can be found online at Tech Trends, published by Springer. Copyright restrictions may apply. doi: 10.1007/s11528-016-0058-z

Email \#2: High Information \& Low Personalization Group

SUBJECT LINE: Your input requested for Student Computing Needs Survey

\section{Hi, \{FIRST NAME $\}$ !}

We recently added $\$ 5.00$ to your —Card in advance of your kind completion of the survey linked below. When you complete the survey, which should take only 10 to 15 minutes of your time, you can register for a random drawing of $\$ 250$.

You are being invited to take this survey because of the unique perspective you have to offer regarding student computing needs on campus. The department and college in which you study will benefit from the feedback offered by concerned students like yourself.

The Committee, offers recommendations about the distribution of student computer fees to units such as colleges and departments. The reason we have developed the survey is to get student input about information technology resources on campus.

As you might be aware, some of the student fees you pay annually are designated for the maintenance and upgrading of designated labs on campus. But are those fees being used in the best way possible? Are the computing resources located in the right places? Is student access to the technology resources adequate? Are more funds needed for a stronger wireless network as more and more students use laptops or other wireless devices? These are the types of questions that we ask, and we hope that you can provide some insight.

Again, we appreciate your time in helping us better understand the needs you have with regard to on-campus technology resources. This information, in turn, will assist us in forming recommendations about how to put computing fees to the best possible use.

To take the survey, \{SURVEY LINK\}

Or copy and paste the URL below into your internet browser:\{SURVEY LINK\}

Best regards,

Members of the

Committee

More info: [URL about survey] 
This is an author-produced, peer-reviewed version of this article. The final, definitive version of this document can be found online at Tech Trends, published by Springer. Copyright restrictions may apply. doi: 10.1007/s11528-016-0058-z

Email \#3: Low Information \& High Personalization Group

SUBJECT LINE: Your input requested for Student Computing Needs Survey

\section{Hi, \{FIRST NAME $\}$ !}

We recently added $\$ 5.00$ to your $\square$ Card in advance of your kind completion of the survey linked below. When you complete the survey, which should take only 10 to 15 minutes of your time, you can register for a random drawing of $\$ 250$.

As a \{CLASS LEVEL\} \{MAJOR\}, you have a unique perspective to offer regarding student computing needs on campus. The \{DEPARTMENT \} will benefit from the feedback offered by concerned \{STATUS\} like yourself.

To take the survey, \{SURVEY LINK\}

Or copy and paste the URL below into your internet browser: \{SURVEY LINK\}

Best regards,

Members of the Committee

More info: [URL about survey]

Email \#4: Low Information \& Low Personalization Group

SUBJECT LINE: Your input requested for Student Computing Needs Survey

\section{Hi, \{FIRST NAME $\}$ !}

We recently added $\$ 5.00$ to your $\quad$ Card in advance of your kind completion of the survey linked below. When you complete the survey, which should take only 10 to 15 minutes of your time, you can register for a random drawing of $\$ 250$.

You are being invited to take this survey because of the unique perspective you have to offer regarding student computing needs on campus. The department and college in which you study will benefit from the feedback offered by concerned students like yourself.

To take the survey, \{SURVEY LINK\}

Or copy and paste the URL below into your internet browser: \{SURVEY LINK\}

Best regards,

Members of the

Committee

More info: [URL about survey] 